\title{
Comparison of the Anomaly of Hydrological Analysis Tools used in Nepal
}

\author{
M. K. Shrestha, S. Chaudhary' ${ }^{1}$ R.K. Maskey ${ }^{2}$ \& G. Rajkarnikar ${ }^{3}$ \\ Email:manojksth@gmail.com \\ ${ }^{1} B$. Tech. Environmental Engineering, Kathmandu University. \\ ${ }^{2}$ Profesor for Hydraulics and Hydropower Engineering School of Engineering Kathmandu University. \\ ${ }^{3}$ Senior Divisional Hydrologist Water and Energy Commusion Secretariat Kathmandu.
}

\begin{abstract}
The diverse physiographic and hydrological regime has booned Nepal with high potential of water resource projects. But these projects depend highly on hydrological data for which hydrometeorological stations need to be established. Their establishment, because of difficult topographic feature of Nepal and the high cost of installation, operation and maintenance, becomes feasible only for big projects. And thus hydrological data are needed to be predicted for small scale projects. These predictions for a given ungauged river system at particular location are facilitated by empirical methods such as WECS/DHM (Water and Energy Commission Secretariat/ Department of Hydrology and Meteorology) and MIP (Medium Irrigation Project) which have been used since its development without upgrading and checking its reliability. The objective of this study is to compare the anomaly of flow predicted by WECS/DHM and MIP method and determine reliability of minimum flow predicted by the methods. The anomaly of the method is presented by comparing the mean DHM monthly flow with the mean of predicted monthly flow for each of the seven rivers from Central and Western Development Region. Both methods give variable deviation for different periods of time for all the rivers. MIP method gives reliable prediction only if the discharge measurement is done during the dry period (November-April). The reliability of these methods is checked for estimating minimum flow by calculating the percentage of time discharge (minimum predicted flow) will be exceeded. WECS/DHM has given higher reliability for the minimum flow than MIP method. MIP (D) method has given good approximation to the DHM dry period flow than MIP (A). While analyzing the low flow, lower predicted value given by either of these methods when used gives good approximation. In order to improve the accuracy of prediction there is requirement of modification of these Hydrological Analytical tools.
\end{abstract}

Keywords: hydrological data; WECS/DHM method; MIP method; ungauged river; $\operatorname{MIP}(D) ; \operatorname{MIP}(A)$

\section{INTRODUCTION}

Nepal is rich in water resources and utilization of water resources through projects such as hydropower or irrigation depends highly upon the hydrological data. Most of the locations of
Nepal lack the sufficient hydro meteorological data because of which vast amount of water resources has remained unexploited at present. In order to evaluate, compare and ultimately develop potential projects hydrological variables of temporal flow condition should be regularly 
monitored. Developing a complete network of hydro-meteorological stations for country like Nepal is expensive. Moreover problems such as lack of efficient manpower, allocation of less resource in collection and processing of hydrologic data and difficult topographic feature are the hindrances for its establishment. Major water resource projects establish their own gauging stations good estimation of flow conditions regarding the water availability and risk minimization relating to the floods. But this is not possible for small scale projects. So it led to the need of methods that could estimate the flow conditions in the ungauged catchment. Several methods and models have been developed for regionalization of hydrologic behavior in Nepal. The most frequently used are:

\section{WECS/DHM METHOD}

It is a modification of WECS approach of 1982 and has been developed jointly by WECS and DHM in cooperation with WMO (World Meteorological Organization), WERDP (Water and Energy Resource Development Project, until 1989) and WISP (WECS/NEA Institutional Support Programme) in 1990. It treats the entire country as a single hydrological region. The regionalization was done for low flows, long term flows and flood flows.

\section{MIP (MEDIUM IRRIGATION PROJECT) METHOD}

Itwas developedin 1982 bySirM.MacDonald and Partners Limited in association with Hunting Technical Services Limited in which Nepal is divided into 7 hydrological regions. No regionalizations were done for either low flows or flood flows. It can only give the mean monthly flows.

\section{RATIONALE OF STUDY}

These two methods are in use for the estimation of the flow conditions for various medium-small scale water resource projects at the ungauged locations. When WECS/DHM method was developed, the country had only 54 hydrological stations which were insufficient to completely represent the country in terms of hydrological regime. So it has made several recommendations of updating the method every five years, developing hydrometric network review and plans, making extensive precipitation study including the Himalayan region and Siwaliks etc.

WECS/DHM has inferred the MIP method as less comprehensive study. This design manual is intended for guidance only and consequently it is not as complete, nor as rigorous, as the WECS (1982) study (WECS/DHM, 1990). The hydrograph developed should be checked or updated so that the prediction made on the basis of the hydrograph is accurate and the discharge predicted could be used.

But these recommendations have not been realized and the method is in use since they are developed. Since there is no other choice for the ungauged locations; these methods are widely relied upon by the water resource projects. As these tools didn't meet the recommendations, it is not wise to fully depend upon their predictions. So this study is to check the anomaly and reliability so that the risk associated with their predictions will be timely avoided. 
3. OBJECTIVE OF STUDY

As their reliability can be questioned, we have the following objectives:

a) To compare anomaly of predicted discharge data by WECS/DHM method and MIP method with gauging station data of DHM

b) To determine the percentage of time, discharge will be exceeded for the lowest discharge predicted by the methods

\section{LITERATURE REVIEW}

Many regional methods for estimating the flow conditions at ungauged sites have been developed in different parts of the world (e.g. Singh (1971); Quimpo et al. (1983); Finnessey and Vogel (1990)). These regionalization methods assume that within a given region, catchments having similar climate, geology, topography, vegetation and soils display similar hydrological responses (Smakhtin, 2001). So, homogenous hydrologic regions are selected for this type of study. Long term and low flow hydrology is particularly dependent upon topography and geology. Hence, different physiographic regions with uniform topographic and geologic characteristics are frequently selected as homogenous hydrologic regions. In Nepal, this is not possible because the drainage basins run approximately north- south while the physiographic regions run approximately east- west. Hydrologic response of the basins as represented by the available stream gauge network is a result of the physical response of several of the physiographic regions contained within the basins. As a result of this problem, it was decided to treat the entire country as a single entity. The two major factors affecting the hydrological characteristics of river is location of catchment area and rainfall in the catchment. Monsoon rainfall contributes to flood runoff which is generally below $3000 \mathrm{~m}$ where as the river above $5000 \mathrm{~m}$ is usually covered with snow mainly contributing to long term flow. The MIP method is based upon measurement taken on an intermittent basis. The measurement of lowest discharge usually April is used to predict the mean monthly discharge of a particular location using a Unit Hydrograph (1/s per sq. Km) which was used to develop Non-dimensional hydrograph for seven regions.

\section{METHODOLOGY}

Seven rivers whose hydrological data has been recorded by DHM were selected whose catchment lies in the MIP regions- either 1 or 3 given in Table 1. We selected those rivers whose catchment ranges within 1000 sq. km and lying in Western and Central Development Region of Nepal. Two rivers from MIP Region 1 and five rivers from MIP Region 3 were selected. The hydrological data from the year 19762006 were taken into account with five years of interval except for Langtang (1993 onward) and Melamchi (1990 onward). 15 meteorological stations were selected to calculate the monsoon wetness index. For each of the river basin at least 3 representative meteorological stations were selected with exception to the Langtang River(2). The Catchment area of the respective river was determined using the Topographical maps of scale 1:25,000 prepared by Survey Department of Government of Nepal in co-operation with government of Finland. 
Table 1: Seven rivers of Central and Western development region

\begin{tabular}{|c|l|l|c|c|c|c|c|}
\hline $\begin{array}{c}\text { Mip } \\
\text { Region }\end{array}$ & Name of River & Location & $\begin{array}{c}\text { Station } \\
\text { Number }\end{array}$ & Latitude & Longitude & Elevation (M) & $\begin{array}{c}\text { Drainge Area } \\
\left(\mathbf{K m}^{2} \mathbf{)}\right.\end{array}$ \\
\hline 1 & Melamchi & Helambu & 627.5 & $28^{\circ} 02^{\prime} \mathrm{N}$ & $85^{\circ} 32^{\prime} \mathrm{E}$ & 2134 & 84 \\
\hline 1 & Langtang & Kenjying & 446.1 & $28^{\circ} 13^{\prime} \mathrm{N}$ & $85^{\circ} 37^{\prime} \mathrm{E}$ & 3920 & 333 \\
\hline 3 & Khimti & Rasnalu & 650 & $27^{\circ} 34^{\prime} \mathrm{N}$ & $86^{\circ} 11^{\prime} \mathrm{E}$ & 1120 & 313 \\
\hline 3 & Solu Khola & Salme & 668.5 & $27^{\circ} 30^{\prime} \mathrm{N}$ & $86^{\circ} 34^{\prime} \mathrm{E}$ & 1800 & 246 \\
\hline 3 & Madi Khola & Shisaghat & 438 & $28^{\circ} 06^{\prime} \mathrm{N}$ & $84^{\circ} 14^{\prime} \mathrm{E}$ & 457 & 858 \\
\hline 3 & Chepe Khola & Gharm besi & 440 & $28^{\circ} 03^{\prime} \mathrm{N}$ & $84^{\circ} 29^{\prime} \mathrm{E}$ & 442 & 304 \\
\hline 3 & Tadi & Belkot & 448 & $27^{\circ} 51^{\prime} \mathrm{N}$ & $85^{\circ} 08^{\prime} \mathrm{E}$ & 475 & 653 \\
\hline
\end{tabular}

The flow was calculated by using both methods. As MIP gives the flow calculation of mean monthly flows, we have considered the calculation of long term flows only for WECS/DHM method for similar comparison. The DHM Stream flow Summary data of corresponding river is taken as reference for comparison.

To determine the reliability among the methods, comparison of WECS/DHM Method and MIP Method (using April flow and the driest monthly flow) against the DHM summary flow data was made. April is considered to be the driest month and so April flow is recommended by the literature for calculation of flows from MIP method. But the DHM summary flow data of seven rivers shows that this consideration does not hold true for all the years and so the attempt is made in this project to predict the flow using MIP method by considering both driest and April flow, designated as MIP(D) and MIP(A), and compare the result of both. Anomaly of WECS/DHM and MIP method is calculated in terms of percentage difference from DHM values. The percentage difference is calculated on the basis of mean discharges. Anomaly shows percentage from which the predicted values are positively or negatively deviated for the respective months from mean DHM values.

Flow Duration Curve of minimum flow was plotted to determine the reliability of these methods in predicting the low flow. This curve is obtained by plotting the discharge against the percentage of time the minimum predicted flow will be exceeded. The discharge taken is the DHM minimum flow of each year. The percentage of time minimum flow predicted by both methods will exceed is then calculated from Flow Duration Curve of minimum flow.

\section{RESULTS AND DISCUSSION}

The anomaly of methods from the DHM data was done on the basis of mean monthly discharge. This has given variable result which is shown in Figures 1- 7. WECS/DHM gives negative deviation for all the months for Melamchi, Khimti, Solu, Madi and Chepe. Comparison against Langtang gives the positive deviation for June December (during monsoon and post monsoon period) which indicates that the modification of the tool is required for the snow fed rivers. But comparison against Tadi gives positive deviation for March - May (during pre-monsoon) which shows that the overall generalization cannot be made for all the rivers of Nepal. MIP (D) gives both positive and negative deviation for both MIP Region I and III. For Region I, MIP (D) gives negative deviation for April and June for Langtang and for Melamchi gives negative deviation for March - November. For Region III, the negative deviation persists between March- 
July for all rivers except Tadi. It gives negative deviation for February and even for AprilNovember (pre monsoon and monsoon period). MIP (A) gives positive deviation for Melamchi and Solu and for other rivers it gives negative deviation for the period between June - July (Khimti), June (Madi), April (Langtang), April - July (Chepe), and June -August (Tadi).

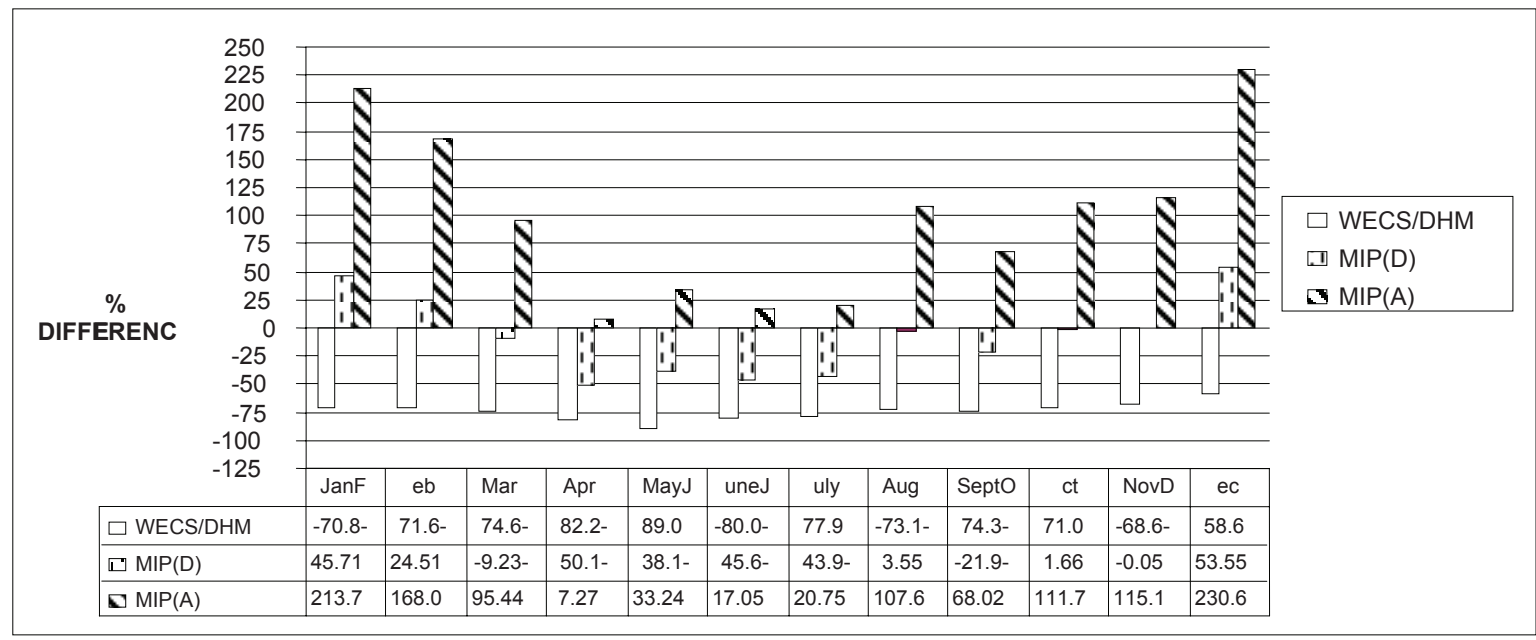

Figure 1: Anomaly of WECS/DHM and MIP - Melamchi

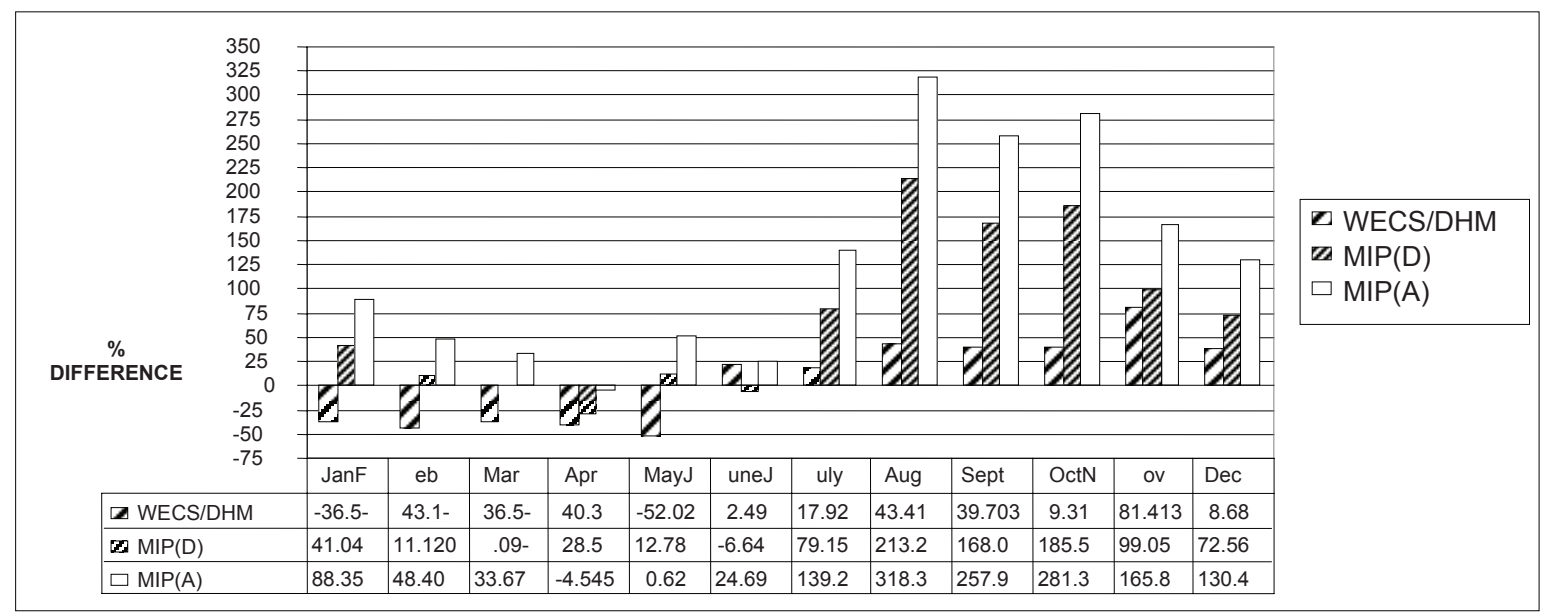

Figure 2: Anomaly of WECS/DHM and MIP - Langtang 


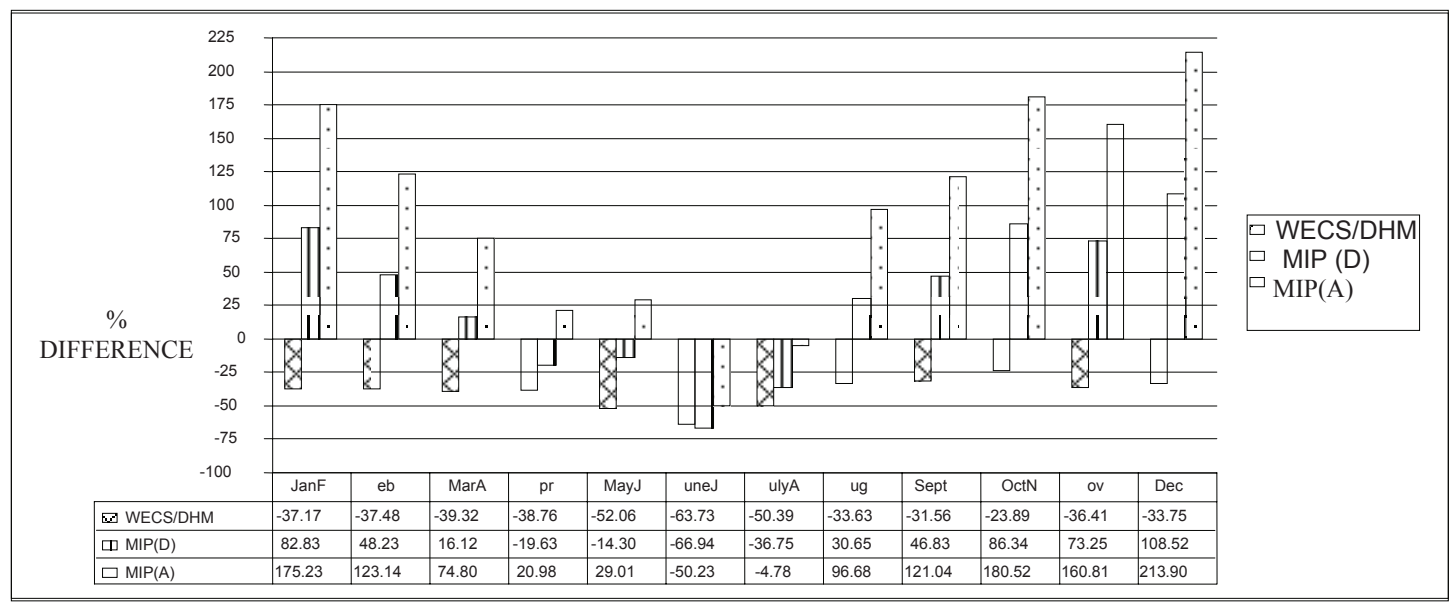

Figure 3: Anomaly of WECS/DHM and MIP - Khimti

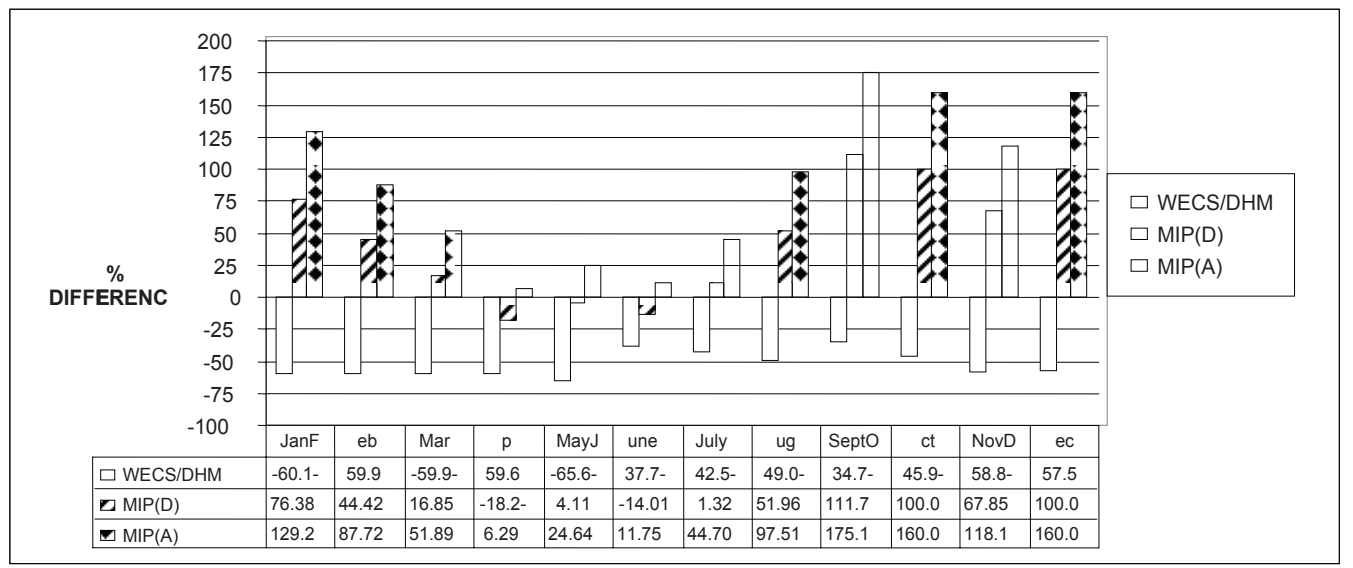

Figure 4: Anomaly of WECS/DHM and MIP - Solu Khola

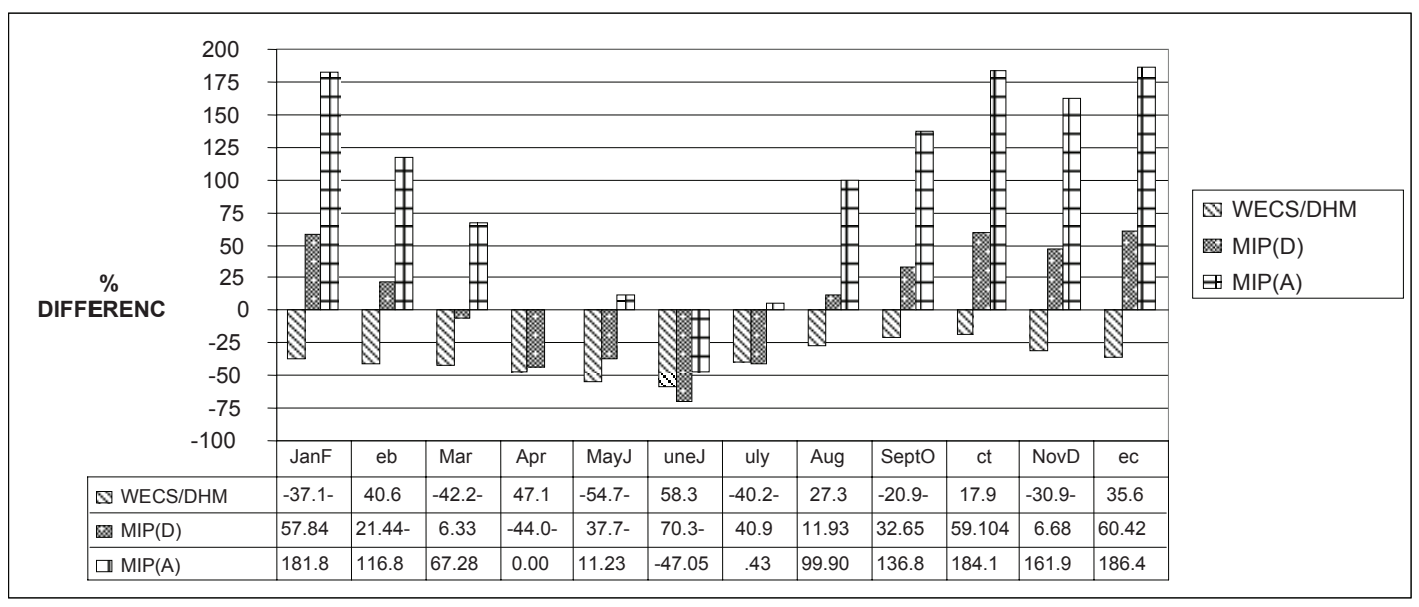

Figure 5: Anomaly of WECS/DHM and MIP- Madi Khola 


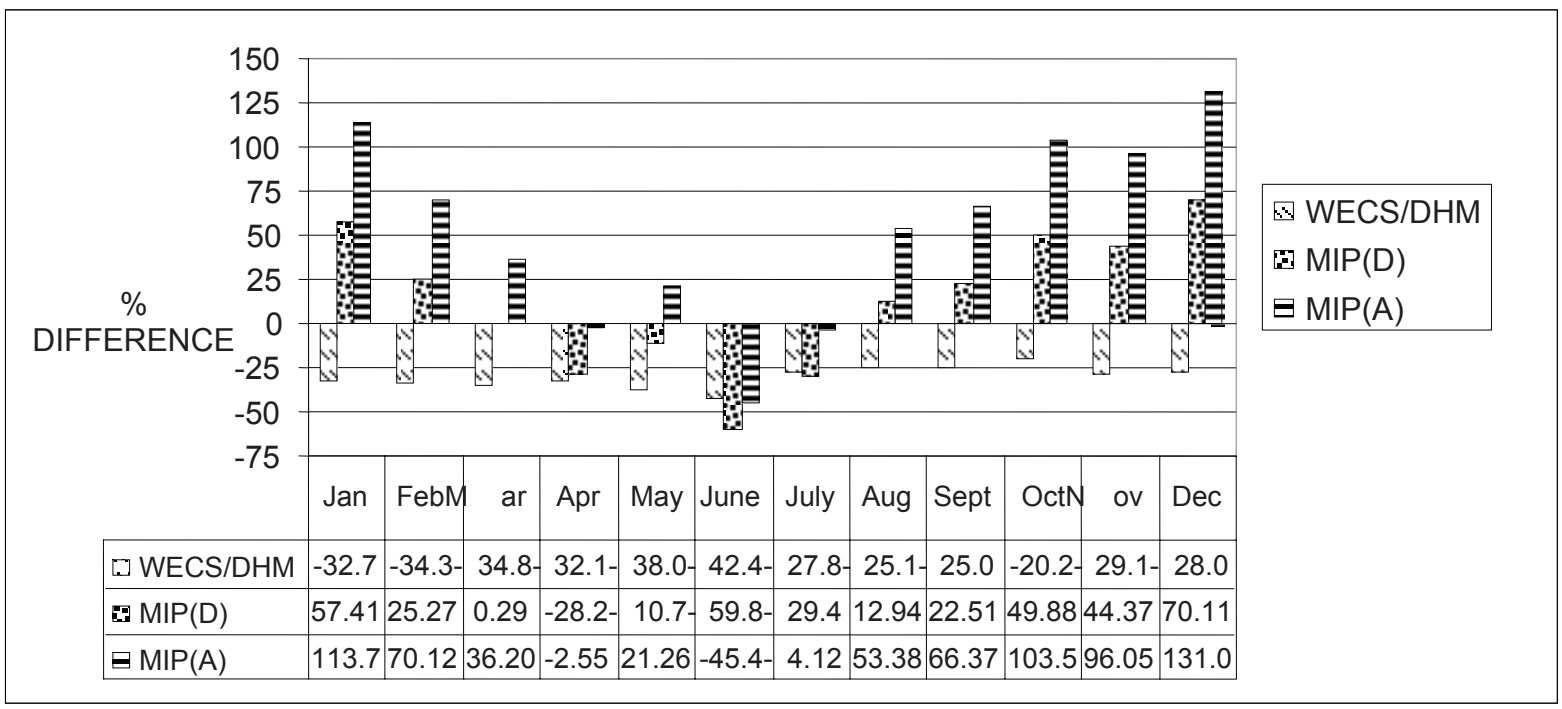

Figure 6: Anomaly of WECS/DHM and MIP - Chepe Khola

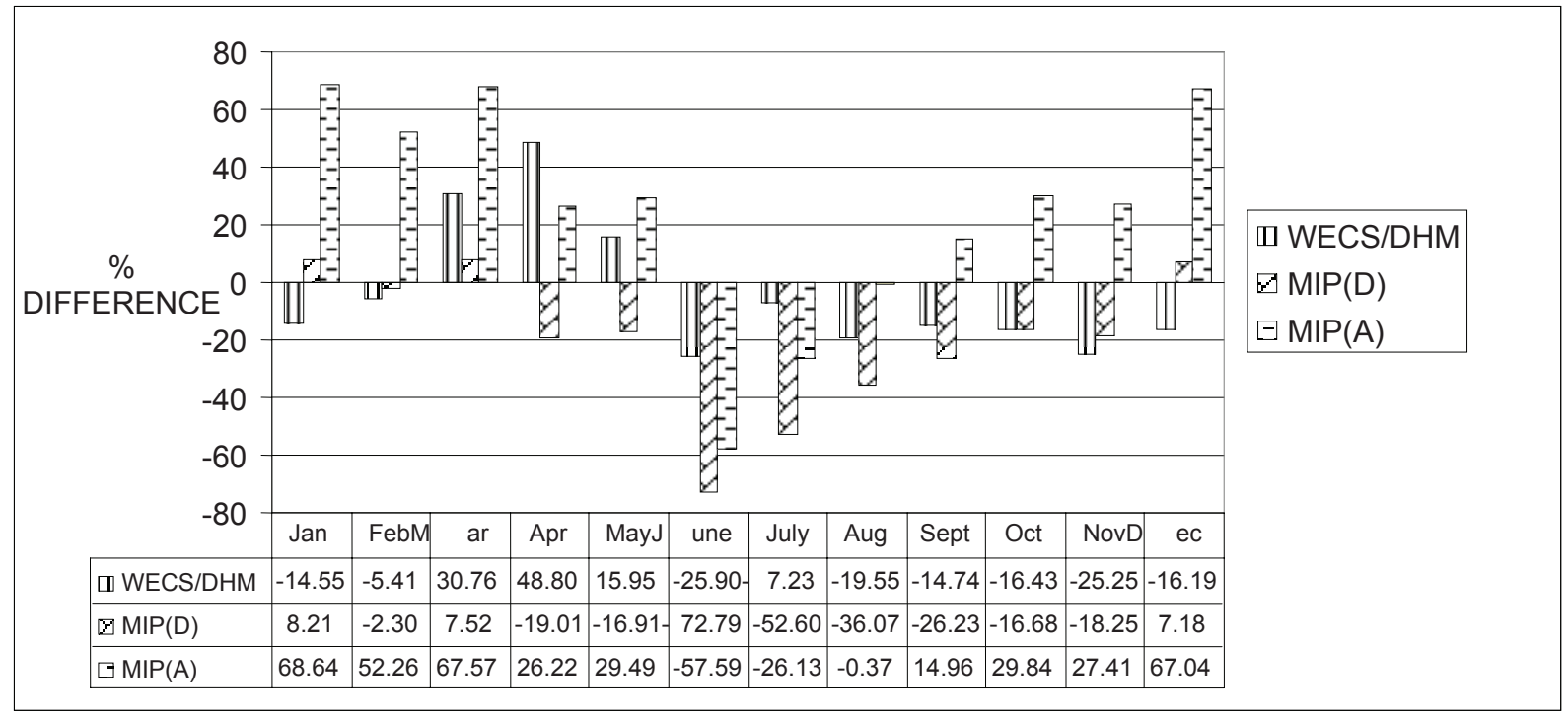

Figure 7:Anomaly of WECS/DHM and MIP - Tadi Khola 


\section{RESULT OF FLOW DURATION CURVE OF MINIMUM FLOW}

The reliability of the lowest predicted flow with the minimum flow of each year for respective river from 1976 - 2006 was calculated by determining the percentage of time the discharge (minimum predicted flow) will be exceeded for both the methods which is given in Table 2. WECS/DHM gives the flow availability of up to $100 \%$ during dry period for Solu Khola. The percentage of reliability for low flow given by WECS/DHM is higher than MIP except for Tadi. The data quality of Tadi is ranked to be good by DHM and so this result cannot be excluded. For MIP (D) the flow availability varies between $24-86 \%$ of time during dry period. But this reliability is valid only if the driest flow could be measured; otherwise this reliability will be reduced as given by MIP (A). As the non dimensional hydrograph ordinate remains same, the greater the flow taken more is the increase in the ordinate of the predicted hydrograph. April is considered to be driest but from the hydrological data of the seven rivers selected the average driest month is March except for Chepe which is April. In the case, when April flow is not the driest, the April flow if taken gives higher predicted value than the driest flow taken i.e., MIP (A) > MIP (D) . So, continuous measurement of the flow between November-April is required to obtain the driest flow. But in the case when this measurement is not possible it is suggested that the flow should be estimated from both the methods and the flow should be so chosen that has lower values.

Table 2: Reliability of minimum flow

\begin{tabular}{|c|c|c|c|c|c|c|c|}
\hline \multirow{2}{*}{ River } & \multirow{2}{*}{$\begin{array}{l}\text { Range of minimum yearly } \\
\text { flow of } \mathrm{DHM}\left(\mathrm{m}^{3} / \mathrm{s}\right)\end{array}$} & \multicolumn{3}{|c|}{ Predicted minimum flow $\left(\mathrm{m}^{3} / \mathrm{s}\right)$} & \multicolumn{3}{|c|}{$\begin{array}{l}\% \text { of Time } Q \text { will be exceeded } \\
\text { for minimum flow }\end{array}$} \\
\hline & & $\begin{array}{c}\text { WECS/ } \\
\text { DHM }\end{array}$ & $\begin{array}{c}\text { MIP } \\
\text { (D) }\end{array}$ & MIP (A) & $\begin{array}{c}\text { WECS/ } \\
\text { DHM }\end{array}$ & $\underset{\text { (D) }}{\text { MIP }}$ & MIP (A) \\
\hline MELAMCHI & $0.47(2000)-3.20(2005)$ & 0.69 & 1.94 & 4.17 & 88 & 59 & $*$ \\
\hline KHIMTI & $1.49(2001)-7.26(1990)$ & 3.04 & 4.22 & 6.35 & 74 & 24 & 5 \\
\hline SOLU & $4.67(2001)-6.48(1996)$ & 2.4 & 5.07 & 6.59 & 100 & 78 & $*$ \\
\hline MADI & $6.34(1993)-17.9(1978)$ & 8.28 & 9.74 & 17.39 & 91 & 86 & 6 \\
\hline CHEPE & $1.37(2001)-4.9(1990)$ & 3 & 3.34 & 4.54 & 66 & 45 & 10 \\
\hline TADI & $0.41(2000)-6.47(1976)$ & 6.32 & 3.76 & 5.87 & 5 & 38 & 7 \\
\hline
\end{tabular}

* - Predicted lowest flow exceeds the range of minimum yearly flow of DHM

Q- Predicted minimum flow

The percentage of time $\mathrm{Q}$ will be exceeded for minimum flow of each river can be inferred from figure of Flow duration curve of minimum flow for respective rivers.

For all the rivers except Tadi the percentage of time $\mathrm{Q}$ will be exceeded for minimum flow is higher for WECS/DHM than MIP. Among three methods, the reliability of minimum flow predicted by MIP (A) is worse. MIP (D) gives good approximation than MIP (A). This higher reliability is obtained only if the driest flow is taken in account.

The Table doesn't include the data for Langtang because of unavailability of data of minimum annual flow. 


\section{CONCLUSION}

The prediction made by these methods gives variable result to conclude that the individual methods are not reliable. However the flow obtained by comparing the predicted flows using both methods could give good approximation but not to the snow fed rivers. But this generates the complexity of using both methods and comparing them and finding one result, which clearly shows the incapability of the single method.

Further MIP depends upon the measured flow. The river flow is very variable even in the same month for different year so it is difficult to predict for future by MIP and has the probability that the water resource project does not sustain long. Also, the result it gives can have good approximation only if the driest flow could be accounted. As the driest flow to be measured could not be predicted it requires continuous flow measurement during the dry periods. To have better future prediction sufficient data is required, which would not be available for the ungauged catchment.

As the number of hydrological station has increased up to 99 from 54 in 1990, it shows the prospect modification and regular update of these methods in each five year interval, as recommended by WECS/DHM. This recommendation shall hold true for MIP as well. This will surely increase the reliability of individual methods and thus help to make the water resource project well sustainable for years.

\section{ACKNOWLEDGEMENT}

The author would like to thank Dr. Rijan Bhakta Kayastha, Assistant Professor, Department of Environmental Science and Engineering, Dr. Keshav Prasad Sharma, Hydrology Division,
Department of Hydrology and Meteorology, Mr. Shyam Sundar Khadka and Miss Silu Bhochibhoya, Research Assistant, Centre for Excellence in Production and Transportation of Electrical Energy (CEPTE/KU), Er. Ishwor Onta and Er. B.P. Shah of East Consult Pvt. Ltd., Basundhara for their help to find reports of Medium Irrigation Project, and Mr. Suresh Maskey, Department of Hydrology and Meteorology for their help during our project study.

\section{REFERENCES}

DHM, 2008. Stream flow Summary (1962-2006), Ministry of Environment Science and Technology, Department of Hydrology and Meteorology, October 2008, pp 177-357

DOI, 1990. Design Manuals for Irrigation Projects in Nepal, 1990. Planning and Design Strengthening Project (PDSP), Ministry of Water Resources, Department of Irrigation. United Nations Development Programme, pp 35-36.

ESAP, 2001. Guidelines Verification of Power Output from Micro-Hydro Plants, 2001. Interim Rural Energy Fund, Alternative Energy Promotion Centre, Energy Sector Assistance Programme, Kathmandu, September, 2001. pp 11-41.

MIP, 1982. Macdonald and Partners Ltd. Medium Irrigation Project, Design Mannual, Hydrology. July, 1982, pp 21-26.

Quimpo, R.G. Alejendrino, A.A. and McNally, T.A., 1983. Regionalized flow duration for Philippines. In: J. Water resource planning and Management, ASCE, pp 320-330. 
Shrestha, H. M., 1985: Water power potential in Nepal: Nature's paradise, White Lotus Co. Ltd., Bangkok, pp 32-35.

Smakhtin, V.U., 2001. Low flow Hydrology: a review. Journal of Hydrology. pp 147-186.

WECS, 1982. Hydrological Studies of Nepal. Volume 1-Report, Voliume 2,3-Appendices, His majesty's Government of Nepal, Ministry of Water Resources Water and
Energy Commission Secretariat and Department of Hydrology and Meteorology, Kathmandu, Nepal, July 1982.

WECS, 1990. Methodology for estimating hydrological characteristics of ungauged locations in Nepal, His majesty's Government of Nepal, Ministry of Water Resources Water and Energy Commission Secretariat and Department of Hydrology and Meteorology, Kathmandu, Nepal, July 1990. 